\title{
PHEROMONALLY INDUCED RELEASE OF LUTEINIZING HORMONE IN MALE MICE: INVOLVEMENT OF THE VOMERONASAL SYSTEM ${ }^{1}$
}

\author{
ARTHUR COQUELIN, ${ }^{*, 2}$ ANDREW N. CLANCY $\ddagger$ FOTEOS MACRIDES, $\ddagger$ ERNEST P. NOBLE, $\S$ AND \\ ROGER A. GORSKI* \\ ${ }^{*}$ Department of Anatomy and Laboratory of Neuroendocrinology of the Brain Research Institute and \$Alcohol Research Center, \\ Department of Psychiatry and Biobehavioral Sciences, University of California, Los Angeles, School of Medicine, \\ Los Angeles, California 90024, and $\ddagger$ The Worcester Foundation for Experimental Biology, Shrewsbury, Massachusetts 01545
}

Received November 23, 1983; Revised March 14, 1984; Accepted March 21, 1984

\begin{abstract}
Evidence has accumulated demonstrating that the vomeronasal (accessory olfactory) system mediates intraspecific chemosensory communication in several mammals. For example, the neuroendocrine effects of priming pheromones in females and the behavioral responses to signaling pheromones in males are disrupted in mice with damage to the vomeronasal system. The experiment reported here examined the potential involvement of the vomeronasal system in the neuroendocrine reflexes observed in male mice following exposure to female and chemosensory stimuli. Excision of the vomeronasal organ (VNO) or sham VNO ablation was performed on sexually experienced males. Next, consecutive blood samples were withdrawn through chronic, intracardiac cannulas while the males were exposed to female mouse urine and then to an ovariectomized female. Plasma levels of luteinizing hormone $(\mathrm{LH})$ were measured in the scquential samples by radioimmunoassay. Removal of the VNO did not affect the spontaneous pattern of episodic LH release that is characteristic of male mice. Reflexive release of $\mathrm{LH}$ following the urine stimulus was blocked in males lacking the VNO, but the female stimulus did cause $\mathrm{LH}$ responses in these mice. Our results therefore demonstrate that the VNO mediates pheromonally induced release of $\mathrm{LH}$ in male mice and that additional cues which emanate from behaving females also effectively stimulate a hormonal response in sexually experienced males.
\end{abstract}

Chemosensory communication is a major vector by which animals can influence the physiology and behavior of their conspecifics. The substances released by mammals often profoundly alter the reproductive processes of the individuals exposed to the stimuli (see reviews in Doty, 1976, and Vandenbergh, 1983). Some compounds, known as priming pheromones, initiate neuroendocrine reflexes, which change the concentrations of circulating hormones and, eventually, can affect both the reproductive physiology and the behavior of the recipients (Bronson, 1974). The priming pheromones emitted by male mice, for example, regulate ovulation in prepubertal and adult females (Whitten, 1956; Vandenbergh, 1967; Bronson and Desjardins, 1974). Mammals also release substances, called signaling pheromones, that evoke prompt behavioral responses by conspecifics (Bronson, 1974). Aggression-stimulating as well as aggression-inhibiting pheromones apparently are released by

${ }^{1}$ This research was supported by United States Public Health Service Fellowships HD 06160 and MH 08645 and Research Grants NS 12344, AA 05555, and HD 01182, and by the Seaver Institute. Reagents used to measure immunoreactive luteinizing hormone were provided by the Rat Pituitary Hormone Distribution Program of the National Institute of Arthritis, Diabetes, and Digestive and Kidney Diseases (NIADDK).

${ }^{2}$ To whom correspondence should be addressed, at Department of Anatomy, University of California, Los Angeles, School of Medicine, Center for the Health Sciences, Los Angeles, CA 90024. male and female mice, respectively (Mackintosh and Grant, 1966; Ropartz, 1968; Dixon and MacKintosh, 1971).

Both priming and signaling pheromones are detected in mammals by nasal chemoreceptors. The vomeronasal (accessory olfactory) system, which is anatomically distinct from the main olfactory system, has been implicated in animals' responses to sex-related pheromones because it communicates with central structures involved in reproductive processes (Keverne, 1979; Wysocki, 1979). From sensory receptors in the vomeronasal organ (VNO), the vomeronasal system projects multisynaptically to the medial amygdaloid nucleus and posteromedial cortical amygdaloid area, the bed nucleus of the stria terminalis, the medial preoptic area, and the ventromedial nucleus of the hypothalamus (Scalia and Winans, 1976; Macrides and Davis, 1983). In addition, disruption of vomeronasal input to the central nervous system inhibits several responses to pheromones. Interrupting vomeronasal afferents eliminates the acceleration of puberty in juvenile females, the suppression of estrous cyclicity in females housed in groups, and the blockade of pregnancy by exposure to unfamiliar males, all of which are responses to priming pheromones in mice (Reynolds and Keverne, 1979; Bellringer et al., 1980; Kaneko et al., 1980). Furthermore, the vomeronasal system is involved in the ultrasonic vocalizations evoked in male mice by female odors and in the agonistic and copulatory behaviors of male mice, all of which are responses to signaling pheromones (Wysocki et al., 1982; Clancy et al., 1984). 
Although the vomeronasal system of mice seems to mediate priming effects in females and signaling effects in males, its potential involvement in males' hormonal responses to priming pheromones has not yet been completely established. Mediation of primer responses by the vomeronasal system in male mice is likely, given the neuroendocrine reflexes that are stimulated by females or by the urine of females (Macrides et al., 1975; Maruniak and Bronson, 1976). In fact, ablation of the VNO in male mice recently has been reported to prevent the elevation of circulating testosterone levels which follows presentation of an anesthetized female (Wysocki et al., 1983). Consequently, the study reported here was designed to examine the role of the VNO in the pheromonally stimulated, reflexive release of luteinizing hormone (LH) in male mice. Our results demonstrate that an intact VNO is not necessary for sexually experienced males to release LH reliably after exposure to a behaviorally active female, but the presence of the VNO is important for the urine of females to evoke the hormonal response.

\section{Materials and Methods}

In this experiment we evaluated the circulating levels of $\mathrm{LH}$ in male mice after surgical removal of the VNO or sham surgery. Sequential samples of blood were withdrawn from freely mobile, chronically cannulated mice while they were being exposed to female mouse urine and then to a gonadcctomized female.

Animals and surgical procedures. The CF-1 mice used in this study were purchased from Charles River Breeding Laboratories, Inc. (Wilmington, MA). Males were oblained at 60 days of age and upon arrival were paired with a sexually mature female in a $29 \times 18 \times 13 \mathrm{~cm}$ polyethylene cage in a colony room. The males cohabited with each of three females for 5 days (total $=15$ consecutive days), and the females were inspected daily for the presence of copulatory plugs. Only males that mated at least once were retained as experimental subjects; they were housed individually during the remainder of the study. Exposure to the social stimuli occurred in each male's home cage. All other mice were housed five per cage in groups of one sex until used as stimulus animals or as donors of blood for transfusion. The animal rooms were maintained at 22 to $24^{\circ} \mathrm{C}$ on a 14-hr light/10-hr dark photoperiod, and Purina Mouse Chow and tap water were always available.

Stimulus females were gonadectomized at 35 to 45 days of age and were used about 1 month later. Urine was obtained from ovariectomized females by gentle abdominal massage, with the excreted fluid being collected on a clean watchglass. Aliquots of fresh urine pooled from several mice were stored frozen until the day the urine was presented to the males as an aerosol spray.

The VNO was excised (VOX group, $n=11$ ) or sham ablations were performed (SHAM group, $n=12$ ) on the sexually experienced males when they were 75 to 80 days old. This protocol is detailed in the preceding paper (Clancy et al., 1984). Briefly, removal of the VNO was achieved using an oral approach. The wounds were sutured and coated with collodian, and the palates were allowed to heal for 1 week. Then, an intracardiac catheter was implanted into each male and its patency was maintained according to procedures previously documented (Coquelin and Bronson, 1980). Cannulated mice received continuous infusions of $0.9 \%$ sodium chloride containing sodium heparin $(5 \mathrm{IU} / \mathrm{ml})$ at $0.3 \mathrm{ml} / 24 \mathrm{hr}$ throughout the postoperative recovery period. Blood samples were obtained beginning 4 to 5 days after the cannulation surgery and commencing within $4 \mathrm{hr}$ of the onset of the light period. The mice were released from their tethers the next day, and 17 of the animals subsequently were included in a series of behavioral studies (Clancy et al., 1984). Finally, the extent of damage to the VNO was evaluated in all of the mice by histological examination of horseradish peroxidase (HRP) reaction product labeling within the accessory and main olfactory bulbs after the mice were sacrificed (Clancy et al., 1984). This procedure and all surgeries were performed using pentobarbital anesthesia.

Blood withdraual and LH assay. Consecutive samples of blood, $30 \mu \mathrm{l}$ each, were obtained at 5 -min intervals through the indwelling cannulas. Samples were kept ice cold until centrifuged for the separation of plasma. Immediately after the removal of each sample, the withdrawn blood was replaced by an equal volume of blood substitute. This substitute consisted of mouse red blood cells obtained from donors of both sexes and suspended in $5 \%$ human plasma protein fraction (Plasmanate; Cutter Laboratories, Inc., Berkeley, CA), with $5 \mathrm{IU} / \mathrm{ml}$ of sodium heparin and 5\% citrate/phosphate/dextrose solution added (Gibson et al., 1957, 1961; Hink et al., 1957). After adjusting the hematocrit to 44 to $46 \%$ (Russell and Bernstein, 1966), the blood substitute was stored at $4^{\circ} \mathrm{C}$ and used within 5 days. Transfusion of this substitute previously has been documented to sustain mice during extended periods of blood sampling (Coquelin and Bronson, 1981; Coquelin and Desjardins, 1982).

The concentration of LH was measured by radioimmunoassay in single $10-\mu$ l aliquots of plasma according to procedures previously validated for use with mouse plasma (Beamer et al., 1972; Coquelin and Bronson, 1980). Entire sets of the consecutive plasma samples from 5,8 , and 10 males, representing members of both VNO surgical treatments, were included in three assays. Unknown LH concentrations were interpolated from a logit-log transformation of the reference curve that had been fit using the four-parameter, iterative method of Rodbard and Hutt (1974). The results are expressed as nanogram-equivalents of NIADDK rat-LH-RP-1 per milliliter of plasma. The minimal amount of LH detected in these assays was $0.20 \mathrm{ng} /$ assay tube or 20 $\mathrm{ng} / \mathrm{ml}$ of plasma. The within-assay coefficient of variation was $8.2 \%$ for six replicates of a mouse serum pool with $221 \pm 13 \mathrm{ng} / \mathrm{ml}$ of $\mathrm{LH}$, and the between-assay coefficient of variation was $24.2 \%$ for the three assays performed during this study.

Exposure of males to social stimuli. In order to evaluate potential effects of VNO ablation upon the characteristic pattern of spontaneous episodic LH release (Coquelin and Desjardins, 1982), 70 consecutive samples of blood were obtained from each of eight VOX and seven SHAM mice in the absence of social stimuli. Next, without interrupting the schedule of blood withdrawal, an $0.1-\mathrm{ml}$ aerosol of pooled female urine was sprayed into the males' home cages (Maruniak and Bronson, 1976). 'Ten blood samples then were collected while the males were exposed to the urinary stimuli. Finally, an ovariectomized female was placed into the cages to interact with the males while the 10 remaining samples of blood were obtained.

The total number of blood samples withdrawn was reduced in another group of mice (VOX $=3$, SHAM $=5$ ) by eliminating the extended preliminary sampling period. Instead, 10 samples were obtained to establish base line levels of $\mathrm{LH}$ before presenting each social stimulus. Ten blood samples again were collected while the males were exposed to the stimuli. Thus, only 40 samples of blood were obtained from these males.

Statistical analysis. An episode of LH release in male mice, whether it occurs spontaneously in the absence of social stimuli or reflexively upon presentation of a social cue, is characterized by a discrete, all-ornothing elevation of hormone above relatively low and stable basal concentrations (Coquelin and Bronson, 1980; Coquelin and Desjardins, 1982). Elevations of LH were defined as episodes of release it the plasma concentration of hormone increased at least $50 \mathrm{ng} / \mathrm{ml}$ above the immediately preceding nadir within $10 \mathrm{~min}$. This definition satisfies statistical as well as physiological criteria: first, such an increment exceeds $4 \mathrm{SD}$ of assay variation at basal concentrations of $\mathrm{LH}$, and second, it is the smallest elevation of LH previously observed to stimulate the secretion of testosterone (Coquelin and Desjardins, 1982). Accordingly, the proportions of males that exhibited LH secretory episodes during the preliminary sampling period or after presentation of either social stimulus were compared using Fisher's exact probability test (Goyette and Mickey, 1975). The mean number of spontaneous episodes, the mean nadir of plasma LH preceding those episodes, and the mean maximum $\mathrm{LH}$ concentration achieved during the secretory episodes were compared between the surgical treatments utilizing single-variable analysis of variance (ANOVA) among only those males that exhibited episodic release (Dixon and Massey, 1969). For those individuals in which multiple spontaneous LH episodes were observed, each male's average nadir and average peak plasma concentration were included in the ANOVA calculations. Finally, the plasma LH concentrations in the consecutive blood samples obtained from all of the males were analyzed using two-variable ANOVA with one repeated measure (Dixon and Massey, 1969). Separate between-group comparisons were made of three 10-sample segments from the entire sequence. These segments were composed of the period before the urine stimulus was presented and the two periods incorporating the social stimuli. In all cases, two-tailed probability values are reported.

\section{Results}

Lavage of the nasal cavity with HRP and subsequent histological examination of $\mathrm{HRP}$ reaction product revealed heavy 
bilateral anterograde labeling in both the main and accessory olfactory bulbs of the SHAM group. Heavy bilateral labeling of the main olfactory bulb with no detectable reaction product within either accessory olfactory bulb was evident in all but one mouse in the VOX group. Therefore, the hormonal measurements from that male are not included in this report. Thus, excision of the VNO from 10 males virtually eliminated its afferent projections to the accessory olfactory bulb, whereas the projections of the VNO remained intact in the 12 mice receiving sham surgeries (see Clancy et al., 1984, for further details).

Examples of the hormone levels that were observed in consecutive samples of blood withdrawn from three males after VNO ablation or sham surgery are illustrated in Figures 1 and 2 , respectively. The upper panels in both figures depict the entire sequences of plasma LH observed in individual males sampled for $7.5 \mathrm{hr}$; the lower two panels of each figure also show plasma $\mathrm{LH}$ in individual males, but they are restricted to the periods when the urinary stimuli and females had been presented. Two spontaneous episodes of LH release are evident in male 32 (Fig. 1, upper panel), whereas five spontaneous elevations observed in male 40 (Fig. 2, upper panel) met the definition for a secretory episode detailed above. Both of these mice released $\mathrm{LH}$ reflexively when a female was placed into their cages (indicated by $\$$ and an arrow in Figs. 1 and 2). Presentation of the urine stimulus (denoted by $u$ and an arrow in Figs. 1 and 2) evoked an LH reflex in the male with an intact VNO (male 40, Fig. 2), but it failed to do so in the mouse lacking its VNO (male 32, Fig. 1). Similarly, two other males that received sham surgery and that are illustrated in the lower panels of Figure 2 also responded to both social stimuli. Although removal of the VNO apparently did not affect the reflexive release of $\mathrm{LH}$ elicited by the presence of a female, VNO ablation eliminated the hormonal response to female urine in most instances (e.g., males 27 and 32 , but see male 58 for a contrary example; Fig. 1).

A comparison of the spontaneous patterns of episodic LH release between the two surgical treatments is presented in Table I. The number of spontaneous episodes exhibited by the individual VOX males ranged from 0 to 3 during the preliminary 6 -hr sampling period, whereas 0 to 5 episodes $/ 6 \mathrm{hr}$ were evident in the SHAM males. The two groups did not differ in the mean number of secretory episodes observed $(F(1,13)=$

TABLE I

Characteristics of the spontaneous pattern of episodic $L H$ secretion in male mice after ablation of the VNO or sham surgery ${ }^{\mathrm{a}}$

\begin{tabular}{lcc}
\hline & \multicolumn{2}{c}{ Vomeronasal Organ } \\
\cline { 2 - 3 } & Removed & Intact \\
Proportion exhibiting episodic LH & $7 / 8$ & $6 / 7$ \\
Number of episodes & $2.3 \pm 0.4(8)$ & $1.7 \pm 0.6(7)$ \\
Nadir LH concentration $(\mathrm{ng} / \mathrm{ml})$ & $28 \pm 3(7)$ & $28 \pm 4(6)$ \\
Peak LH concentration $(\mathrm{ng} / \mathrm{ml})$ & $222 \pm 36(7)$ & $165 \pm 27(6)$ \\
\hline
\end{tabular}

${ }^{a}$ Values are mean \pm SEM; numbers in parentheses, number of subjects. No statistically significant differences were observed in these parameters.

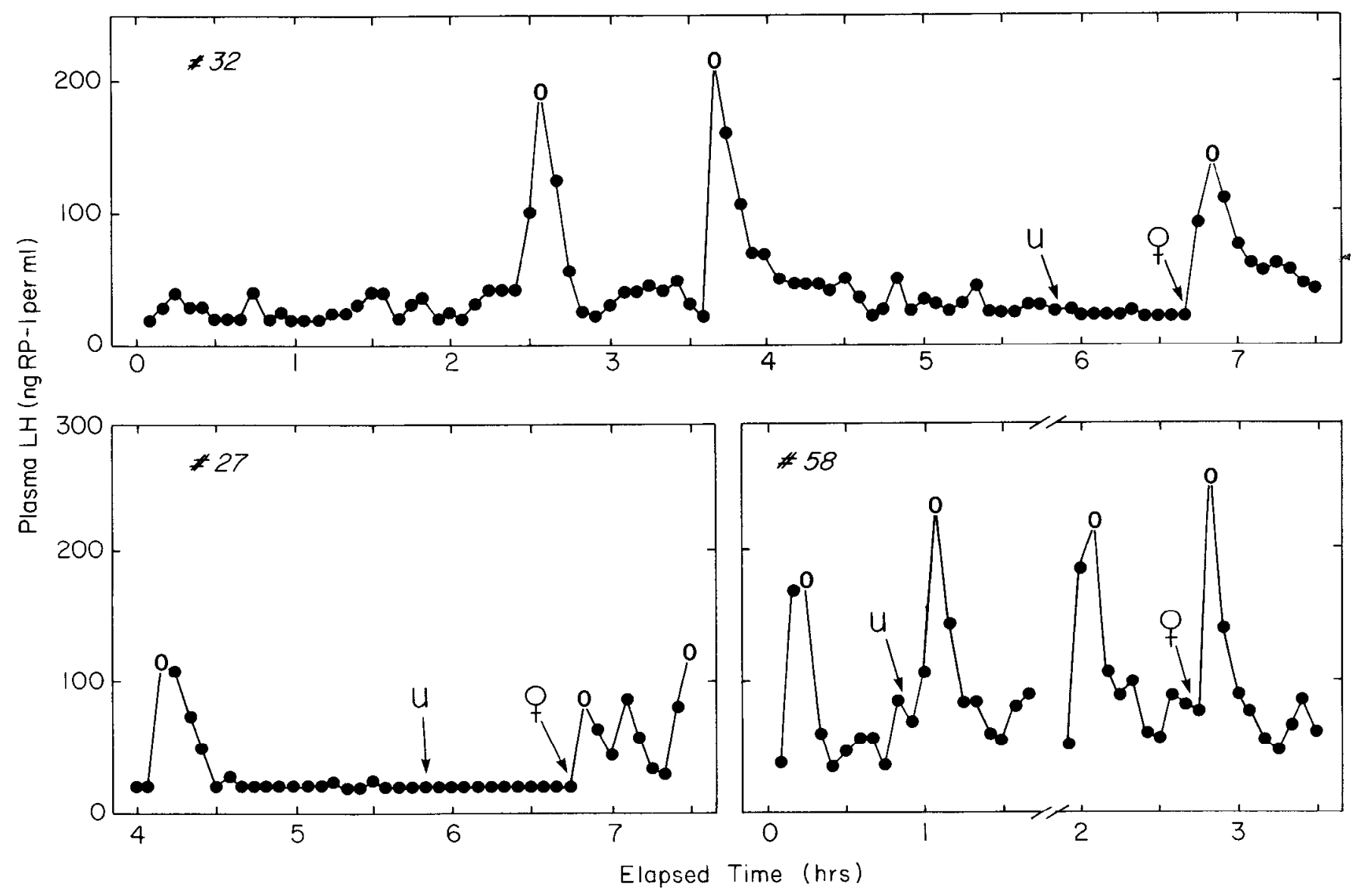

Figure 1. Concentrations of LH in the plasma of three representative male mice after removal of their VNOs. Each panel represents the secretory pattern of an individual male. The symbols depict the concentration of hormone in single samples of blood; the open symbols mark the peaks of those hormonal elevations that met the criteria for an LH secretory episode. A urine stimulus $(u)$ and a female stimulus ( $($ ) were presented at the times indicated by the arrows. 


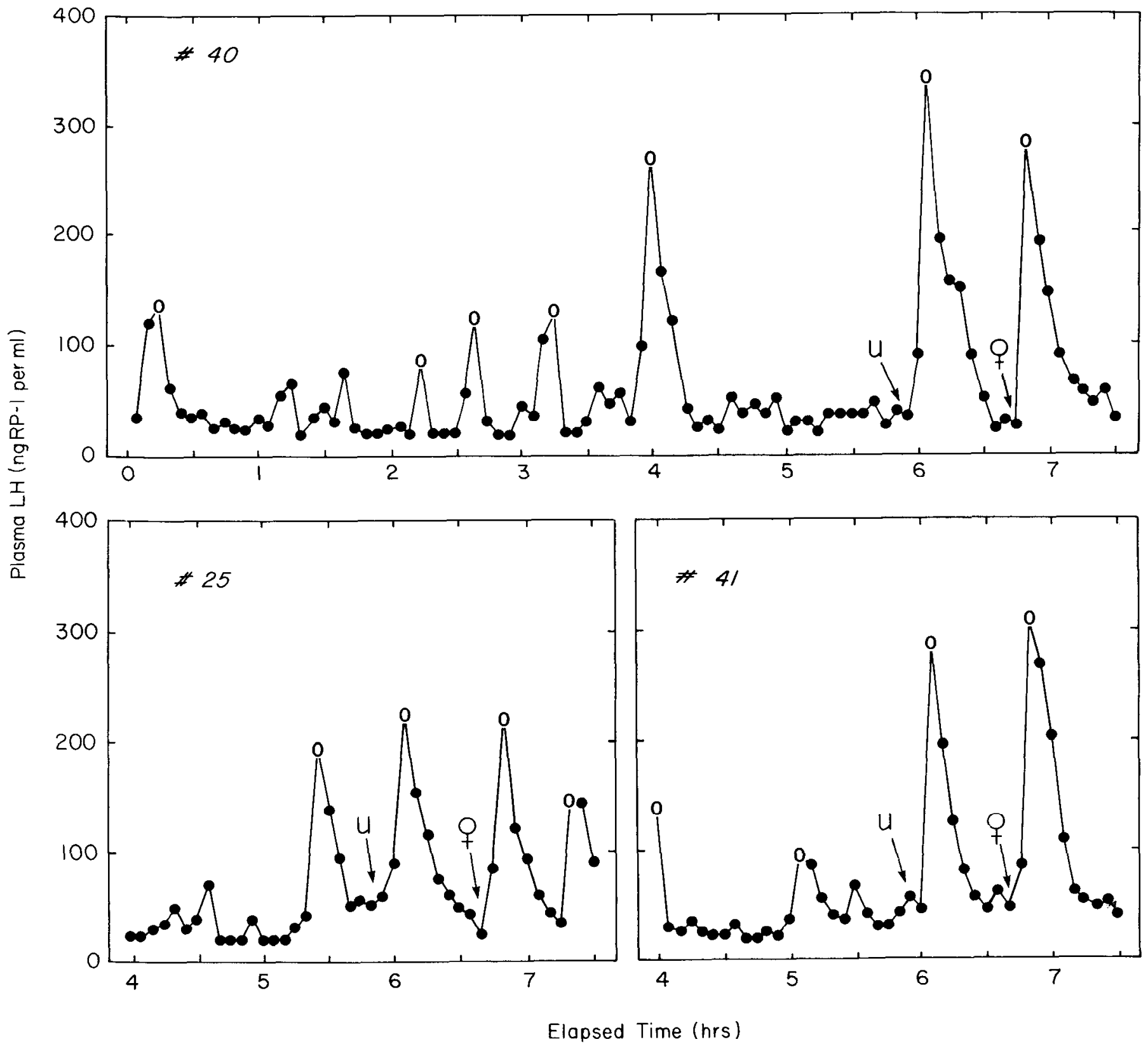

Figure 2. Concentrations of LH in the plasma of three representative male mice after sham VNO ablation. Each panel represents the secretory pattern of an individual male. The symbols depict the concentration of hormone in single samples of blood; the open symbols mark the peaks of those hormonal elevations that met the criteria for an LH secretory episode. A urine stimulus and a female stimulus ( $u$ and $q$, respectively) were presented at the times indicated by the arrows.

$0.61, p>0.25$ ), nor did they differ in regard to the mean nadir or the mean peak plasma LH concentrations exhibited during the spontaneous episodes $(F(1,11)=0.00, p>0.99$, and $F(1,11)$ $=1.54, p>0.10$, respectively; Table I).

Male mice lacking their VNOs were significantly less responsive to female urine than were sham-operated animals as evidenced by the observation that only 4 of 10 VOX mice as compared with 11 of 12 SHAM animals exhibited reflexive $\mathrm{LH}$ surges $(p=0.02)$. However, the animals of both groups responded to freely behaving conspecific females as evidenced by the observation that 9 of 10 VOX mice and 11 of 12 SHAM animals exhibited reflexive LH responses $(p=1.00)$. Inspection of the basal LH records of all animals revealed that several mice had spontaneous episodes of LH release immediately before the presentation of the social stimuli. In a subsequent statistical analysis such records were deleted, and the resulting data are presented in Table II. The rationale for omitting those
TABLE II

Comparison of the reflexive $L H$ release evoked by two types of social stimuli in male mice after removal of the VNO or sham surgery ${ }^{a}$

\begin{tabular}{lcc}
\hline & \multicolumn{2}{c}{ Vomeronasal Organ } \\
\cline { 2 - 3 } & Removed & Intact \\
\hline Urine Stimulus & & \\
$\quad$ Proportion exhibiting LH reflex & $2 / 7^{\circ}$ & $10 / 11$ \\
$\quad$ Peak LH concentration $(\mathrm{ng} / \mathrm{ml})$ & $186 \pm 44(2)$ & $237 \pm 21(10)$ \\
Female Stimulus & & \\
$\quad$ Proportion exhibiting LH reflex & $8 / 9$ & $9 / 9$ \\
$\quad$ Peak LH concentration $(\mathrm{ng} / \mathrm{ml})$ & $192 \pm 32(8)$ & $236 \pm 20(9)$ \\
\hline
\end{tabular}

${ }^{a}$ Values are mean \pm SEM; numbers in parentheses, number of subjects.

${ }^{b}$ Significantly fewer than males with VNO intact; $p=0.01$, Fisher's exact probability test. 
records is that a refractory period exists following an initial release of LH during which there is a low probability of any stimulus evoking a second LH episode (Coquelin and Bronson, 1981), and the absence of a hormonal response to the test stimulus presented within the refractory period might therefore be misinterpreted as a direct effect of VNO ablation. The result of this more conservative procedure was to remove one to three records from each cell of the $2 \times 2$ (VNO status $\times$ social stimulus) matrix, leaving between 7 and 11 response sequences available for analysis in the four cells shown in Table II. By this analysis, the proportion of males exhibiting an LH response to the urine stimulus again was significantly lower in the mice lacking a VNO relative to those mice with the VNO intact $(p=0.01)$. However, after the female stimulus, there was no difference between the VOX and SHAM groups in the proportions of males releasing LH $(p=1.00)$. Among the males that did respond to the social stimuli, the release of LH reached the same peak concentration in the two surgical groups (urine stimulus: $F(1,10)=1.02, p>0.25$; female stimulus: $F(1,15)=$ $1.39, p>0.25)$.

The mean concentrations of plasma $\mathrm{LH}$ that were observed in consecutive samples of blood obtained from all of the mice under the various stimulus conditions are illustrated in Figure 3 . The upper panel of this figure shows the LH responses that were evoked in the group of males lacking their VNO, and the pattern of $\mathrm{LH}$ release elicited in the males receiving only sham
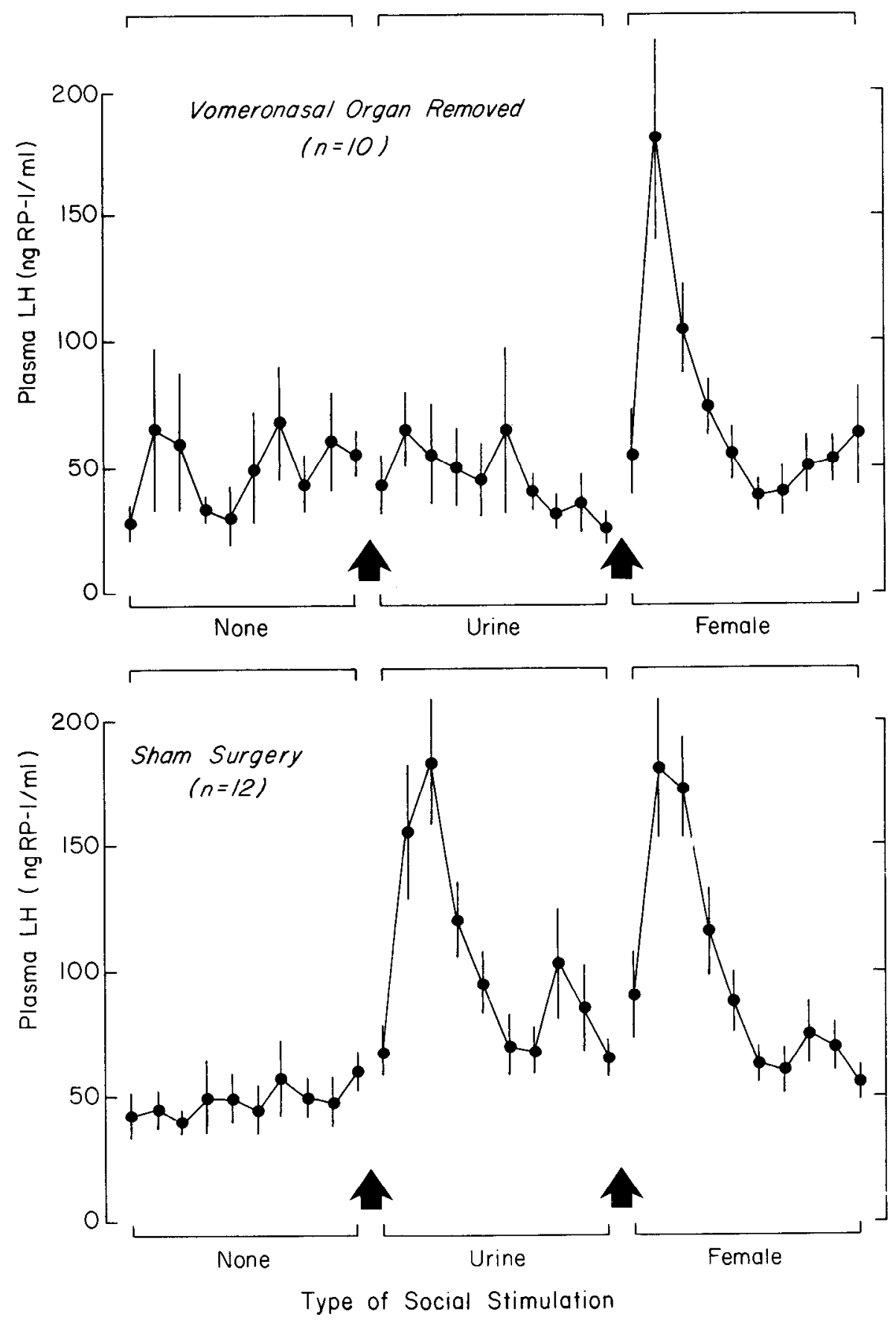

Figure 3. Plasma LH concentrations (Mean \pm SEM) in male mice during their exposure to two different social stimuli. The onset of each stimulus is denoted by an arrow. Top panel, Secretion of LH that is evoked in male mice after removal of the VNO. Bottom panel, LH responses induced in male mice with intact VNOs. 
surgery is shown in the lower panel. LH secretion did not differ between the groups in the absence of social stimuli (ANOVA of VOX versus SHAM: $F(1,20)=0.00, p>0.99$ ). When the urine stimulus was presented to the males with VNO ablation, no elevation of circulating $\mathrm{LH}$ was observed. A surge of $\mathrm{LH}$ was evoked, however, when the urine stimulus was presented to the males with an intact VNO (ANOVA of VOX versus SHAM: $F(1,20)=13.77, p<0.005)$. LH responses clearly followed the presentation of a female stimulus to both groups of mice, but the overall mean hormonal response of the SHAM males was larger than that of the VOX males (mean $\pm \mathrm{SEM}$ $\mathrm{SHAM}=97 \pm 6 \mathrm{ng}$ of $\mathrm{LH} / \mathrm{ml}$ versus $\mathrm{VOX}=72 \pm 7 \mathrm{ng}$ of $\mathrm{LH} /$ $\mathrm{ml} ; F(1,20)=6.13, p<0.05)$.

\section{Discussion}

The results of this experiment demonstrate that removal of the VNO from male mice selectively blocks their LH responses to female urine. Peripheral deafferentation of the accessory olfactory bulb does not interrupt these males' release of hormone elicited by exposure to a freely behaving female. Because the spontaneous pattern of episodic LH release and the occurrence of the female-induced LH reflex that are characteristic of male mice were unaffected by the surgical treatment, the loss of responsiveness to female urine cannot be attributed to an effect of VNO excision upon the LH releasing system, per se. Hence, the VNO in male mice appears to be the major detector of priming pheromones dispersed in the urine of females. This function of the vomeronasal system in male mice seems analogous to its clearly documented role in the responses of female mice to pheromones (Reynolds and Keverne, 1979; Bellringer et al., 1980; Kaneko et al., 1980).

It is curious that $40 \%$ of the males with VNO ablation did release $\mathrm{LH}$ after exposure to female urine. Three of these four mice subsequently were given the opportunity to copulate with sexually receptive females, yet none actually achieved intromission or ejaculation (Clancy et al., 1984). Like the other mice in the VOX group, these four males had considerable copulatory experience before virtually total disruption of the VNO afferents (as assessed by the absence of HRP labeling in the accessory olfactory bulb; Clancy et al., 1984). Due to the episodic nature of LH secretion, some of the apparent responses to urine in the VOX males might in fact have been spontaneous LH surges. However, it is also possible that this result reflects involvement of the main olfactory system in the control of LH release, particularly with respect to conditioned responses. In male rats, an olfactory cue from a decidedly non-female originodor of wintergreen-has been shown by Graham and Desjardins (1980) to cause a neuroendocrine reflex when the conditioned stimulus previously had been associated with females in a sexual context. Such conditioned responses might also occur in male mice toward previously inactive urinary constituents or to other female-associated stimuli. Whether novel olfactory cues or normally inactive urinary constituents can be associated with reproductive processes in the absence of vomeronasal input remains to be determined. Likewise, the specific sensory system utilized by a sexually naive mouse to identify correctly its first mate has not been characterized, although the vomeronasal system obviously should be considered.

The involvement of additional sensory modalities in this neuroendocrine reflex is evidenced directly by our finding that $\mathrm{LH}$ responses were stimulated by the presence of a female in males lacking the VNO. Our observation complements the report by Wysocki et al. (1983) that anesthetized females failed to cause testosterone responses in male mice after removal of the VNO. These two experiments differ qualitatively in the presence or absence of behavioral activity on the part of the stimulus female. The sexually experienced males in our study therefore could have responded to a multitude of female-origi- nating cues, including visual and auditory, which were not available to the males in the other study. That multiple sensory systems might be involved in this hormonal response is not a novel postulate, since a tactile cue associated with ejaculation previously has been shown to cause the reflexive release of $\mathrm{LH}$ in mice (Coquelin and Bronson, 1980). Instead, this idea emphasizes the redundancy in and the physiological significance of the neural systems that link gender identification of conspecifics with reproductive hormone secretion in male mice.

The statistical difference in the overall mean plasma $\mathrm{LH}$ levels after female exposure between the males lacking their VNO and the males with their VNO intact is intriguing (Fig. 3 ). Because the VNO-ablated and sham-operated groups did not differ in their LH secretion in the absence of social stimuli or in the mean peak amplitude of their hormonal responses to females, this difference in mean LH levels during the female exposure period suggests that the males with intact VNO input on average experienced a more prolonged release or slower clearance of LH than the males lacking such input. Thus, although this result does not invalidate the basic concept of an all-or-nothing episode of LH release (Coquelin and Bronson, 1980), the durations of individual secretory episodes or hormonal disappearance rates may be influenced to some extent by sensory and/or behavioral variables (cf. Clancy et al., 1984).

In summary, this experiment has clearly demonstrated that the vomeronasal system of male mice is of major importance for the detection of priming pheromones in the urine of females. The release of LH that normally is elicited by female urine was blocked in male mice after excision of their VNOs. This hormonal response is not mediated exclusively by the vomeronasal system because these sexually experienced males released $\mathrm{LH}$ when a behaviorally active female was presented. Hence, the vomeronasal system appears to be one of several sensory systems capable of initiating reproductively significant neuroendocrine reflexes.

\section{References}

Beamer, W. G., S. M. Murr, and I. I. Geschwind (1972) Radioimmunoassay of mouse luteinizing and follicle-stimulating hormones. Endocrinology 90: 823-827.

Bellringer, J. F., H. P. M. Pratt, and E. B. Keverne (1980) Involvement of the vomeronasal organ and prolactin in pheromonal induction of delayed implantation in mice. J. Reprod. Fertil. 59: 223-228.

Bronson, F. H. (1974) Pheromonal influences on reproductive activities in rodents. In Pheromones, M. C. Birch, ed., pp. 344-365, Elsevier, New York.

Bronson, F. H., and C. Desjardins (1974) Circulating concentrations of FSH, LH, estradiol, and progesterone associated with acute maleinduced puberty in female mice. Endocrinology 94: 1658-1668.

Clancy, A. N., A. Coquelin, F. Macrides, R. A. Gorski, and E. P. Noble (1984) Sexual behavior and aggression in male mice: Involvement of the vomeronasal system. J. Neurosci. 4: 2222-2229.

Coquelin, A., and F. H. Bronson (1980) Secretion of luteinizing hormone in male mice: Factors that influence release during sexual encounters. Endocrinology 106: 1224-1229.

Coquelin, A., and F. H. Bronson (1981) Episodic release of luteinizing hormone in male mice: Antagonism by a neural refractory period. Endocrinology 109: 1605-1610.

Coquelin, A., and C. Desjardins (1982) Luteinizing hormone and testosterone secretion in young and old male mice. Am. J. Physiol. 243: E257-E263.

Dixon, A. K., and J. H. Mackintosh (1971) Effect of female urine on the social behavior of adult male mice. Anim. Behav. 19: 138-140.

Dixon, W. J., and F. J. Massey, Jr. (1969) Introduction to Statistical Analysis, Ed. 3, McGraw-Hill, New York.

Doty, R. L. (1976) Mammalian Olfaction, Reproductive Processes, and Behavior, Academic Press, Inc., New York.

Gibson, J. G., II, S. B. Rees, T. J. McManus, and W. A. Scheitlin (1957) A citrate-phosphate-dextrose solution for the preservation of human blood. Am. J. Clin. Pathol. 26: 855-873.

Gibson, J. G., II, C. B. Gregory, and L. N. Button (1961) Citrate- 
phosphate-dextrose solution for preservation of human blood: A further report. Transfusion 1: 280-287.

Goyette, D., and M. R. Mickey (1975) Chi square probabilities for $2 \times$ 2 tables. BMDP Technical Report No. 15. UCLA Health Sciences Computing Facility, Los Angeles.

Graham, J. M., and C. Desjardins (1980) Classical conditioning: Induction of luteinizing hormone and testosterone secretion in anticipation of sexual activity. Science 210: 1039-1041.

Hink, J. H., Jr., J. Hildago, V. P. Seeberg, and F. F. Johnson (1957) Preparation and properties of a heat-treated human plasma protein fraction. Vox Sang. 2: 174-186.

Kaneko, N., E. A. Debski, M. C. Wilson, and W. K. Whitten (1980) Puberty acceleration in mice. II. Evidence that the vomeronasal organ is a receptor for the primer pheromone in male mouse urine. Biol. Reprod. 22: 873-878.

Keverne, E. B. (1979) Dual olfactory projections and their significance for behavior. In Chemical Ecology: Odour Communication in Animals, F. J. Ritter, ed., pp. 75-83, Elsevier-North Holland Publishing Co., Amsterdam.

Mackintosh, J. H., and E. C. Grant (1966) The effect of olfactory stimuli on the agonistic behavior of laboratory mice. Z. Tierpsychol. 23: 584-587.

Macrides, F., A. Bartke, and S. Dalterio (1975) Strange females increase plasma testosterone levels in male mice. Science 189: 1104 -1106.

Macrides, F., and B. J. Davis (1983) The olfactory bulb. In Chemical Neuroanatomy, P. C. Emson, ed., pp. 391-426, Raven Press, New York.

Maruniak, J. A., and F. H. Bronson (1976) Gonadotropic responses of male mice to female urine. Endocrinology 99: 963-969.

Reynolds, J., and E. B. Keverne (1979) The accessory olfactory system and its role in the pheromonally mediated suppression of oestrus in grouped mice. J. Reprod. Fertil. 57: 31-35.
Rodbard, D., and D. M. Hutt (1974) Statistical analysis of radioimmunoassays and immunoradiometric (labeled antibody) assays: A generalized, weighted, iterative, least-squares method for logistic curve fitting. In Symposium on RIA and Related Procedures in Clinical Medicine and Research, pp. 165-192, International Atomic Energy Agency, Vienna, Austria.

Ropartz, P. (1968) The relation between olfactory stimulation and aggressive behavior in mice. Anim. Behav. 16: 97-100.

Russell, E. S., and S. E. Bernstein (1966) Blood and blood formation. In Biology of the Laboratory Mouse Ed. 2, E. L. Green, ed., pp. 351372, McGraw-Hill, New York.

Scalia, F., and S. S. Winans (1976) New perspectives on the morphology of the olfactory system: Olfactory and vomeronasal pathways in mammals. In Mammalian Olfaction, Reproductive Processes and Behavior, R. L. Doty, ed., pp. 7-28, Academic Press, Inc., New York.

Vandenbergh, J. G. (1967) Effects of the presence of a male on the sexual maturation of female mice. Endocrinology 81: 345-349.

Vandenbergh, J. G. (1983) Pheromones and Reproduction in Mammals, Academic Press, Inc., New York.

Whitten, W. K. (1956) Modifications of the oestrus cycle of the mouse by external stimuli associated with the male. J. Endocrinol. 13: 399404.

Wysocki, C. J. (1979) Neurobehavioral evidence for the involvement of the vomeronasal system in mammalian reproduction. Neurosci. Biobehav, Rev. 3: 301-341.

Wysocki, C. J., J. Nyby, G. Whitney, G. K. Beauchamp, and Y. Katz (1982) The vomeronasal organ: Primary role in mouse chemosensory gender recognition. Physiol. Behav. 29: 315-327.

Wysocki, C. J., Y. Katz, and R. Bernhard (1983) Male vomeronasal organ mediates female-induced testosterone surges in mice. Biol. Reprod. 28: 917-922. 